\title{
The Inner Image of Russian Color Term Черный (Black) (Experimental Study)
}

\author{
Elena Tanygina ${ }^{1}$ \\ ${ }^{1}$ Southwest State University, Foreign Languages Department, 94, 50 Let Oktyabrya Street, 305040, Kursk, Russia.
}

\begin{abstract}
The article deals with the description of the method of investigating main features of color terms inner image in the consciousness of the bearers of modern Russian culture by the example of Russian color term черный [chernyj] (black). The theoretical basis of the study is A.A. Zalevskaya's conception of individual knowledge and Sharifian's conception of distributed emergent cultural cognition. The complex approach to the study of color terms using psycholinguistic methods and methods of statistical data processing is shown in the article. The following techniques are used: the association experiment, the semantic differential, the factor analysis. This research study was performed at Southwest State University in Kursk (Russia). The experiment showed that there is a connection between individual and cultural knowledge in the process of color terms' inner image formation.
\end{abstract}

\section{Introduction}

Nowadays the group of color terms (CT) is one of the most intriguing and promising spheres for a linguistic study. "The natural objects that we are surrounded with virtually always contain many different shades of color, yet the visual system usually categorizes them into a single color category" [1]. Of particular interest is the question of how our knowledge of color as physical and mental phenomenon is related to our knowledge of color naming. On the one hand, it seems that the meaning of CT can be easily determined from the position of physics, i.e. specifying the wavelength and intensity of a color shade. This approach cannot reveal the full meaning of CT from the point of view of linguistics. In terms of physics, all people percept color in the same way. However, linguistic conceptualization of colors, though there are some similarities. is different in different cultures. Why so? Language reflects what is happening in the mind while our mind is formed under the influence of the surrounding culture. There is a certain color image in the mind of any native speaker of a language. This image affects the personal life and even shapes personal behavior. According to the research conducted by $\mathrm{Y}$. Hsieh, $\mathrm{H}$. Chiu, Y. Tang, M. Lee the online consumers' reactions to online prices vary according to website background colors [2].

'Language consciousness' has many different levels and contains both facts lying on the surface and other facts that are hidden very deeply. It is important to distinguish between silent knowledge, which is hidden in the 'depths' of human consciousness, but can be pulled to the surface, and scientific knowledge, which naive carriers may simply not have. The latter is not reflected in the language and does not play any role in linguistic research. So, when a usual native speaker uses a color name he/she never thinks of its physical characteristics. It means that color is first of all not the name of a physical value but mostly it is the name of a cultural phenomenon.

To understand the nature of this cultural phenomenon we can use the theory of individual knowledge developed by Prof. A. A. Zalevskaya. According to the conception, language knowledge for an individual does not exist by itself, it exists only in the context of a person's diverse experience formed through his/her personal everyday activities. In this sense the word is a means of access to the human knowledge base, to the information thesaurus. A. A. Zalevskaya thinks that it is necessary to distinguish between individual and collective knowledge. Individual knowledge is understood not as the knowledge content which is specific for a certain individual (which is according to A. A. Zalevskaya is termed 'personal knowledge'), but as special knowledge aspects that have formed in accordance with consistent mental activity patterns under the influence and control of norms and values developed in a social environment [3].

The concept of collective knowledge is associated with the concept of cultural knowledge. An attempt to determine the structure of cultural knowledge was made by Australian scientist F. Sharifian, who proposed a model of distributed emergent cultural cognition. $\mathrm{He}$ treats knowledge as a culturally conditioned phenomenon belonging to a group of people rather than to an individual. It results from the interaction of people belonging to the same culture [4].

\footnotetext{
* Corresponding author: eabel@yandex.ru
} 


\section{Materials and methods}

The material is the Russian language. The authors studied the Russian language in general and specific features of Russian lexeme черный ${ }^{1}$ [chernyj] (black) in particular. Our earlier studies we devoted to CT красный (red), фиолетовый (violet) and розовый (pink). As this is a psycholinguistic study the actual object of the study is not the word черный (black) as a part of a Russian language system but the inner image of Russian CT черный (black) in the consciousness of the Russian culture bearers. We based our research on the psycholinguistic doctrine of the word of A. A. Zalevskaya [8], F. Sharifian's concept of cultural knowledge [4] as well as on some theoretical statements expressed by A. P. Vasilevich [9] and R. M. Frumkina [10].

To do our research we used psycholinguistic methods and methods of statistical data processing: the association experiment (AE), the definitional analysis, the semantic differential (SD) and the factor analysis (FA). The aim of the study was to identify the specific features of the 'inner image' of СТ черный (black) in the consciousness of Russian culture bearers.

Also, having studied the relations between knowledge and nomination and the relations between individual and cultural knowledge in the formation of the inner image of the word in individual's mind [4, 8], we clearly understood that the only way to get inner image of a word is to conduct an extensive association experiment.

\section{Results and discussion}

The study of the peculiarities of CT inner image in the consciousness of a native speaker was based on the assumption that there are some differences between the cultural image of CT and their 'inner image' in the consciousness of an ordinary native speaker. The experimental study involved first and second year students of Southwest State University aged from 17 to 21 years (67 people (42 boys and 25 girls), Russian language speakers). In the research we used the free association method. The respondents were asked to write the first words that came to their minds on the given stimuli, the number of reactions was not limited.

As a result we obtained 143 responses, 24 of the reactions were repetitive ones (i.e. the reactions mentioned more than once) (see Table 1).

Table 1. AE results.

\begin{tabular}{|l|l|}
\hline \multicolumn{1}{|c|}{ Boys } & \multicolumn{2}{|c|}{ Girls } \\
\hline Night (9), death (6), oil (4), wheels & Night (5), death (3), \\
(3), goth (3), earth (3), Raven (3), & mourning (3), grief \\
coffee (3), square (2), cat (2), & (2), cloak (2), \\
Boomer (2), African American (2), & sadness \\
mourning (2), sea (1), sadness (1), & landscape (2), door \\
Gothic (1), killer whale (1), crash & (2), dress (2), \\
(1), stealth (1), sweater (1), serious & darkness (2), sweater \\
\hline
\end{tabular}

${ }^{1}$ The research was conducted based on the material of the Russian language. So the names of CT are given in Russian with the translation into English

\begin{tabular}{|c|c|}
\hline $\begin{array}{l}\text { (1), darkness (1), cats (1), eye- } \\
\text { catching (1), bright (1), Pepsi (1), } \\
\text { snow (1), stylish (1), car (1), } \\
\text { Malevich square (1), cosmos (1), } \\
\text { mantle (1), darkness (1), guitar (1), } \\
\text { screen (1), Ghost (1), jacket (1), } \\
\text { catfish (1), suspense (1), band (1), } \\
\text { haze (1), void (1), Niger (1), } \\
\text { turtleneck (1), mouse (1), economy } \\
\text { (1), metals (1), color (1), poverty } \\
\text { (1), war (1), terrible (1), brick (1), } \\
\text { Negroes (1), textbook (1), Barack } \\
\text { Obama (1), circle (1), triangle (1), } \\
\text { parallelepiped (1), tie (1), table (1). }\end{array}$ & $\begin{array}{l}\text { (1), headband (1), } \\
\text { earth (1), pain (1), } \\
\text { severity (1), velvet } \\
(1) \text {, barn (1), angry } \\
(1) \text { furious (1), } \\
\text { classic (1), gloomy } \\
\text { (2), strict (1), square } \\
\text { (1), gloom (1), bad } \\
\text { mood (1), darkness } \\
(1) \text {, evil (1), screen } \\
(1) \text {, suit (1), groom } \\
(1) \text { terrorist (1), } \\
\text { unknown } \\
\text { pragmatic } \\
\text { business (1). (1), }\end{array}$ \\
\hline
\end{tabular}

Let's consider the results. Further, in the course of the analysis of the materials the reactions obtained during the $\mathrm{AE}$ are treated as individual knowledge and the lexicographic sources data as cultural knowledge.

From the point of view of physics a black object is a body that has close to zero albedo - an indicator of the incident light reflection. For example, the coal albedo is about 0.04 . Let's consider cultural knowledge about the studied CT, i.e. the meaning of the word fixed in the dictionary. While studying dictionary entries of several authors it is possible to gain general concept about cultural knowledge concerning this or that phenomenon of surrounding reality. Having studied the explanatory dictionaries of the Russian language $[11,12,12]$ we found out that Russian word черный (black) has the following lexico-semantic variants (LSV): LSV1 - 'the colors of soot, coal'; LSV2 - 'darker than normal color (about having been in the sun, dirty, darkened)'; LSV3 'designed for any service or domestic needs, not the main, not the front'; LSV4 - 'unskilled, auxiliary, not requiring high skill, physically heavy or dirty (about work)'; LSV5 - 'negative, bad'; LSV6 - 'gloomy, joyless, heavy, sad'; LSV7 - 'malicious, low, treacherous, criminal'; LSV8 'the one who has skin of black or dark color'; LSV9 'destructive, debilitating (about the disease)'; LSV10 'deceitful, dirty, fake (about PR)'; LSV11 - 'illegally obtained, hidden from taxation (income, money)'; LSV12 - 'associated with the supernatural forces of nature or with evil forces, with Satan, with the Devil and capable of causing harm to someone; sorcerer (about magic)'; LSV13 - 'not privately owned; state (in Russia of the 9th - 13th centuries)'.

It can be noted that in the respondents' reactions not all the meanings of the word черный (black) recorded in the dictionary were actualized (in our study there were no reactions related to LSV13, LSV11, LSV10, LSV4). For example, LSV1 and LSV2 mainly describe what color in our culture is considered to be black while in respondents' reactions the language speakers' individual knowledge shows which subjects are considered to be CТ черный (black) prototypes. It is noteworthy that this particular CT is the most metaphorical for the Russian language speakers as the number of subject associations for this 
color is minimal. Among the subject associations to this CT the following reactions are present: oil (4), earth (4), wheels (3), cat (3), coffee (3), door (2), screen (2), orca (1), sweater (1), Pepsi (1), machine (1), guitar (1), jacket (1), catfish (1), turtleneck (1), mouse (1), textbook (1), tie (1), table (1), sweater (1), rim (1), costume (1), mantle (1), velvet (1). Thus, in the mind of a modern young person LSV1 can be transformed into 'color of oil, earth'. Since the earth has different colors in different parts of the world it is easy to argue with this definition. However, our study was conducted in the city of Kursk which is located in the Central Black Soil Region of Russia. In this case we can say that the earth is black here. However, few of the respondents saw oil with their own eyes (which is also not black at all). That is, this concept arose solely due to the expression 'black gold' which is often used in relation to oil. Another reason for it can be oil fountains or objects stained with oil, the color of which due to the peculiarities of the color rendition of video and photographic equipment can be taken for black.

LSV8 is realized in the reactions of the subjects not only by direct indication of a person with a certain skin color (niger, African American). It also indicates a person of a given skin color (Barack Obama). Although neither a Negro nor Barack Obama are black in the understanding of this color.

Some people associate черный (black) with the bridegroom (a rare case when черный (black) is associated with something really having black color - the bridegroom's suit). Others associate it with a terrorist (there is probably a collective opinion formed by displaying TV images of terrorists, their heads usually covered with black cloth).

We concluded that many objects of the real world are considered to have 'blackness' only on the basis of some internal concepts of their color. The examples are land, oil, wheels, Pepsi. That is, a person knows what black color is in reality and conventionally gives the name black to the objects that are associated with this color though they actually may not be black. It may be interesting that the experiment demonstrated that almost all black items perceived like physically black are man-made, that is, made by a man with his ideas about black (bridegroom's suit, terrorists' scarf) and not made by nature. None of the interviewees mentioned the association night sky, which is also black. The reason is that night here is associated with the state of a person changing in accordance with the daily cycle and not with the object or phenomenon of the material world. So when there is an association night a person tries to imagine what he feels at night.

The results of the experiment also showed the respondents' negative attitude to black color which can be the reflection of the cultural knowledge of its traditional symbols. Black means night, death, repentance, decay, sin, destructive forces, silence and emptiness. 'Since black absorbs all other colors it also expresses denial and despair, symbolizes grief and mourning'(in Russian) [14]. It is not surprising that among the associations for this CT there are such reactions as death (9), darkness (5), mourning (5), sadness (3), gloomy (3), grief (2), evil (2), uncertainty (2), sadness (2), poverty (1), pain (1), war (1), collapse (1), terrible (1), haze (1), emptiness (1).
The group of associations which can be united under the general name 'a funeral' includes death, mourning (which is closely connected with death), partly sadness, gloomy, grief (for these states death is not obligatory, but these states are consequences of death). It reflects the dictionary meanings of CT черный (black) (see LSV5 (terrible), LSV6 (gloomy, sad) and LSV7 (evil)). However, there are some peculiarities of this use which will be discussed further. We termed this group 'funerals' to emphasize when a person may encounter what he means by the words death, mourning, etc. Black itself is not associated with death, but it is an indispensable attribute of the funerals, a distinctive feature of the funeral procession. It would be logical to expect such an association, but no one gave it. This association is replaced by certain abstractions, such as death and mourning, perhaps because the latter are ephemeral in the minds of any person, and the funeral is quite specific, scary and unpleasant event, especially for young people. This can be the reason for the symbolic use of CT черный (black) (mourning, death, sorrow) and for the negative attitude to it. It is difficult to understand what is primary here: a negative attitude to black (at the level of physiological reactions of the human nervous system) and its association with the main negative event in human life (death) or a negative attitude to death which is associated with black for some reason. We can assume the second since only in the European cultural tradition black color is associated with death.

Further we conducted a research using the SD method. This method was used to study the emotional relationship and its connection with the inner image of CT черный (black). The SD is a research technique developed in 1950s in the USA by professor Osgood (Osgood, 1957) for measuring individual psychological meanings of words or attitudes towards something. The method focuses on simple evaluation of opinions and thus it is especially suitable for measuring emotional and behavioral aspects of the attitude (Hewstone, 2006). The differential method is a combination of controlled association and scaling procedures [15]. The main aim of the SD method is to construct a semantic space. This structure can be used as an explanatory model to find out how an individual perceives, classifies, compares, and evaluates given objects or their characteristics [16].The connection of the SD method with the AE method is shown in the works of K. Noble, A. Staats and K. Staats. The scientists proved the presence of a high correlation between the Osgood's pragmatic value and Noble's measure of an associative connectivity of words [17]. The main advantage of this method is its easy administration and relatively fast evaluation. Initially, this method was developed for measuring the connotative meaning of concepts, where each concept can be expressed as a point in semantic space. Each concept is usually evaluated in respect to the following three factors: Evaluation factor, Potency (power) factor, Activity factor [18]. The SD in psycholinguistics is a method of quantitative and qualitative 'indexing' (evaluation) of the meaning of a word using bipolar scales, each of which has a gradation with a pair of antonymic adjectives [19]. As the concepts' estimates on different scales correlate with each other it is 
possible to group them into factors with the help of the FA.

Our experiment was held among 80 Russian interviewees ( 48 boys and 32 girls), first and second year students of Southwest State University aged from 17 to 21 . The respondents were given the instruction to evaluate each CT according to twenty bipolar scales (Table 2).

Table 2. SD scales.

\begin{tabular}{|c|l|c|l|}
\hline № & \multicolumn{1}{|c|}{ Name } & № & \multicolumn{1}{c|}{ Name } \\
\hline 1 & pleasant - unpleasant & 11 & good - bad \\
\hline 2 & happy - sad & 12 & masculine - feminine \\
\hline 3 & warm - cold & 13 & strong - weak \\
\hline 4 & active - passive & 14 & aggressive - peaceful \\
\hline 5 & relaxed - stressful & 15 & formal - informal \\
\hline 6 & funny - serious & 16 & $\begin{array}{l}\text { soothing - } \\
\text { stimulating }\end{array}$ \\
\hline 7 & dynamic - static & 17 & preffered - regected \\
\hline 8 & emotional - rational & 18 & kind - evil \\
\hline 9 & beautiful - ugly & 19 & positive - negative \\
\hline 10 & sincere - insincere & 20 & cheerful - sad \\
\hline
\end{tabular}

The choice of the scales was determined by the requirements to the selection of scales for the study using the SD, i.e. the metaphoricity of the scale, the universality of the scale. [20]. The study was conducted with a sevenpoint scale which allows to identify both the quality and the intensity of the value of the studied characteristics.

The interviewees were given the following instructions 'Evaluate each of the proposed colors for each of the characteristics, on a scale from +3 to -3 in accordance with your feelings. Using $\mathrm{X}$ mark the place on the scale that best describes your opinion. Please try to give your evaluation to each characteristic'.

At the first stage of the results processing we analyzed the average values on the scales (arithmetic mean, mean deviation) and calculated the number of different answers for each scale. To confirm the conclusions made on the basis of the primary analysis the following characteristics were found: the mathematical expectation (the average of all estimates), the standard deviation (the 'spread' of estimates), the kurtosis (the 'sharpness' of the maximum and the absence of side maxima) and the mode. Further, we calculated the percentage of positive and negative estimates.

At the second stage of data processing we carried out the FA using STATISTICA package implementing procedures for data analysis, data management, data mining, and data visualization. To process the results we chose the Equamax normalized method which helps to combine all correlating features into factors with the highest percentage of occurrence. As a result of the processing we calculated individual factors' loads and identified factor structures.

Consider the results obtained in the FA (see Table 3).

Table 3. FA (boys' results)

\begin{tabular}{|l|l|l|l|l|l|}
\hline & F1 & F2 & F3 & F4 & F5 \\
\hline $\begin{array}{l}\text { pleasant }- \\
\text { unpleasant }\end{array}$ & 0,334 & 0,408 & 0,655 & 0,056 & 0,006 \\
\hline
\end{tabular}

\begin{tabular}{|l|l|l|l|l|l|}
\hline happy - sad & 0,210 & $-0,012$ & $\mathbf{0 , 8 4 3}$ & $-0,061$ & $-0,141$ \\
\hline warm - cold & 0,323 & $-0,104$ & $\mathbf{0 , 7 4 4}$ & 0,223 & $-0,199$ \\
\hline $\begin{array}{l}\text { active } \\
\text { passive }\end{array}$ & $-0,082$ & 0,296 & $\mathbf{0 , 7 6 3}$ & 0,246 & $-0,026$ \\
\hline $\begin{array}{l}\text { relaxed - } \\
\text { stressful }\end{array}$ & 0,599 & $-0,142$ & 0,268 & 0,367 & 0,334 \\
\hline $\begin{array}{l}\text { funny - } \\
\text { serious }\end{array}$ & $-0,195$ & $-0,657$ & 0,136 & 0,341 & 0,246 \\
\hline $\begin{array}{l}\text { dynamic - } \\
\text { static }\end{array}$ & $-0,180$ & $-0,142$ & $\mathbf{0 , 7 1 2}$ & 0,184 & 0,441 \\
\hline $\begin{array}{l}\text { emotional }- \\
\text { rational }\end{array}$ & 0,023 & 0,017 & 0,100 & $\mathbf{0 , 8 1 9}$ & 0,108 \\
\hline $\begin{array}{l}\text { beautiful - } \\
\text { ugly }\end{array}$ & 0,335 & 0,638 & 0,409 & $-0,188$ & 0,164 \\
\hline $\begin{array}{l}\text { sincere } \\
\text { insincere }\end{array}$ & 0,403 & 0,331 & 0,127 & 0,574 & 0,083 \\
\hline good - bad & $\mathbf{0 , 7 2 9}$ & 0,481 & 0,130 & 0,212 & 0,124 \\
\hline $\begin{array}{l}\text { masculine - } \\
\text { feminine }\end{array}$ & $-0,175$ & $\mathbf{0 , 7 6 7}$ & 0,157 & 0,053 & 0,149 \\
\hline $\begin{array}{l}\text { strong } \\
\text { weak }\end{array}$ & $-0,065$ & $\mathbf{0 , 8 7 5}$ & $-0,003$ & 0,152 & $-0,137$ \\
\hline $\begin{array}{l}\text { aggressive - } \\
\text { peaceful }\end{array}$ & $-0,318$ & $\mathbf{0 , 7 0 6}$ & 0,134 & 0,291 & $-0,088$ \\
\hline $\begin{array}{l}\text { formal } \\
\text { informal }\end{array}$ & $-0,048$ & 0,009 & 0,135 & $-0,155$ & $\mathbf{- 0 , 8 7 9}$ \\
\hline $\begin{array}{l}\text { soothing - } \\
\text { stimulating }\end{array}$ & $\mathbf{0 , 7 2 2}$ & $-0,246$ & $-0,109$ & 0,067 & $-0,230$ \\
\hline $\begin{array}{l}\text { preferred - } \\
\text { rejected }\end{array}$ & 0,250 & 0,597 & 0,508 & $-0,163$ & 0,187 \\
\hline kind - evil & 0,618 & $-0,160$ & 0,415 & $-0,140$ & 0,024 \\
\hline $\begin{array}{l}\text { positive - } \\
\text { negative }\end{array}$ & 0,687 & 0,111 & 0,340 & $-0,061$ & 0,007 \\
\hline $\begin{array}{l}\text { cheerful - } \\
\text { sad }\end{array}$ & 0,049 & 0,209 & $\mathbf{0 , 8 5 2}$ & $-0,103$ & $-0,052$ \\
\hline Expl.Var & $\mathbf{3 , 0 6 4}$ & $\mathbf{3 , 8 4 6}$ & $\mathbf{4 , 4 2 3}$ & $\mathbf{1 , 6 7 0}$ & $\mathbf{1 , 3 8 0}$ \\
\hline Prp.Totl & $\mathbf{0 , 1 5 3}$ & $\mathbf{0 , 1 9 2}$ & $\mathbf{0 , 2 2 4}$ & $\mathbf{0 , 0 8 9}$ & $\mathbf{0 , 0 6 2}$ \\
\hline
\end{tabular}

Table 4. FA (girls' results)

\begin{tabular}{|c|c|c|c|c|c|}
\hline & F1 & F2 & F3 & F4 & F5 \\
\hline $\begin{array}{l}\text { pleasant - } \\
\text { unpleasant }\end{array}$ & 0,879 & $\begin{array}{c}- \\
0,121\end{array}$ & 0,140 & 0,034 & 0,117 \\
\hline happy - sad & 0,550 & $\begin{array}{c}- \\
0,058 \\
\end{array}$ & 0,324 & 0,010 & 0,567 \\
\hline $\begin{array}{l}\text { warm - } \\
\text { cold }\end{array}$ & 0,288 & 0,162 & $-0,014$ & $-0,173$ & 0,747 \\
\hline $\begin{array}{l}\text { active - } \\
\text { passive }\end{array}$ & 0,306 & 0,140 & 0,763 & 0,108 & 0,423 \\
\hline $\begin{array}{l}\text { relaxed - } \\
\text { stressful }\end{array}$ & 0,331 & $\begin{array}{c}- \\
0,052\end{array}$ & 0,024 & 0,671 & 0,212 \\
\hline $\begin{array}{l}\text { funny - } \\
\text { serious }\end{array}$ & $-0,058$ & 0,153 & $-0,436$ & 0,328 & 0,443 \\
\hline $\begin{array}{l}\text { dynamic - } \\
\text { static }\end{array}$ & 0,190 & 0,678 & 0,438 & $-0,081$ & $-0,092$ \\
\hline $\begin{array}{l}\text { emotional - } \\
\text { rational }\end{array}$ & 0,295 & 0,158 & 0,746 & 0,143 & 0,104 \\
\hline $\begin{array}{l}\text { beautiful - } \\
\text { ugly }\end{array}$ & 0,816 & 0,180 & $-0,032$ & $-0,031$ & 0,044 \\
\hline $\begin{array}{l}\text { sincere - } \\
\text { insincere }\end{array}$ & 0,173 & 0,220 & 0,233 & 0,738 & $-0,127$ \\
\hline good-bad & 0,802 & 0,280 & 0,217 & 0,064 & 0,120 \\
\hline $\begin{array}{l}\text { masculine - } \\
\text { feminine }\end{array}$ & 0,087 & $\begin{array}{c}- \\
0,049 \\
\end{array}$ & $-0,089$ & 0,843 & $-0,149$ \\
\hline $\begin{array}{l}\text { strong - } \\
\text { weak }\end{array}$ & 0,571 & $\begin{array}{c}- \\
0,320\end{array}$ & 0,036 & 0,350 & $-0,346$ \\
\hline
\end{tabular}




\begin{tabular}{|c|c|c|c|c|c|}
\hline $\begin{array}{l}\text { aggressive } \\
\text { - peaceful }\end{array}$ & $-0,075$ & 0,061 & $-0,157$ & 0,042 & $-0,758$ \\
\hline $\begin{array}{l}\text { formal - } \\
\text { informal }\end{array}$ & 0,414 & 0,116 & 0,275 & 0,308 & $-0,255$ \\
\hline $\begin{array}{l}\text { soothing - } \\
\text { stimulating }\end{array}$ & 0,632 & 0,288 & $-0,288$ & 0,163 & 0,018 \\
\hline $\begin{array}{l}\text { preffered - } \\
\text { regected }\end{array}$ & 0,842 & $\begin{array}{c}- \\
0,146\end{array}$ & 0,121 & 0,001 & $-0,005$ \\
\hline kind - evil & 0,522 & 0,374 & $-0,019$ & 0,203 & 0,327 \\
\hline $\begin{array}{l}\text { positive - } \\
\text { negative }\end{array}$ & 0,620 & 0,572 & 0,091 & 0,061 & 0,225 \\
\hline $\begin{array}{l}\text { cheerful - } \\
\text { sad }\end{array}$ & 0,311 & 0,708 & $-0,015$ & 0,108 & 0,078 \\
\hline Expl.Var & 5,197 & 1,927 & 1,965 & 2,191 & 2,310 \\
\hline Prp.Totl & 0,260 & 0,096 & 0,098 & 0,110 & 0,116 \\
\hline
\end{tabular}

Let us consider in detail the FA results obtained for СТ черный (black). In this case the program identifies five factors both in boys' and girls' answers that combine into the following factors (Table 5):

Table 5. Factors

\begin{tabular}{|c|c|c|c|}
\hline \multicolumn{2}{|c|}{ Boys } & \multicolumn{2}{|c|}{ Girls } \\
\hline $\begin{array}{l}\text { EVALUAT } \\
\text { ION }\end{array}$ & $\begin{array}{c}\mathrm{good} / \mathrm{bad} \\
\text { soothing/stim } \\
\text { ulating }\end{array}$ & $\begin{array}{c}\text { EVALUAT } \\
\text { ION }\end{array}$ & $\begin{array}{c}\text { pleasant/ } \\
\text { unpleasant } \\
\text { beautiful/ugl } \\
\text { y } \\
\text { good/bad, } \\
\text { preffered/reg } \\
\text { ected } \\
\end{array}$ \\
\hline potency & $\begin{array}{c}\text { masculine/fe } \\
\text { minine } \\
\text { strong/weak } \\
\text { aggressive/pe } \\
\text { aceful }\end{array}$ & SADNESS & happy/sad \\
\hline ACTIVITY & $\begin{array}{c}\text { happy/sad } \\
\text { warm/cold } \\
\text { active/passiv } \\
\mathrm{e} \\
\text { dynamic/stati } \\
\mathrm{c} \\
\text { cheerful/sad }\end{array}$ & ACTIVITY & $\begin{array}{c}\text { active/passiv } \\
\mathrm{e} \\
\text { emotional/ra } \\
\text { tional }\end{array}$ \\
\hline $\begin{array}{c}\text { EMOTION } \\
\text { ALITY }\end{array}$ & $\begin{array}{c}\text { emotional/rat } \\
\text { ional }\end{array}$ & $\begin{array}{l}\text { MASCULI } \\
\text { NITY }\end{array}$ & $\begin{array}{c}\text { masculine/fe } \\
\text { minine } \\
\text { sincere/insin } \\
\text { cere }\end{array}$ \\
\hline $\begin{array}{c}\text { FORMALI } \\
\text { TY }\end{array}$ & $\begin{array}{c}\text { formal/infor } \\
\text { mal }\end{array}$ & $\begin{array}{l}\text { BELLIGER } \\
\text { ENCE }\end{array}$ & $\begin{array}{c}\text { aggressive/p } \\
\text { eaceful } \\
\text { warm/cold }\end{array}$ \\
\hline
\end{tabular}

We propose the analysis of the respondents' answers distribution curves after the FA as one of the research methods. If the distribution is normal the factor can show some of the respondents' inclinations (depending on what the average shows) or the absence of specific associations with this color. If the distribution is closer to the Poisson or geometric there is some external influence on this factor (from the point of view of mathematical statistics there is a dominating factor that forces to give certain answers). We think that personal associations and cultural knowledge about colors are the reason of this phenomenon.

The program identifies five factors in boys' answers. In our opinion, the first three factors can be considered as the most significant for СТ черный (black) since they have the greatest load. In this case the factor 'potency' is the most important. Let's make a histogram for the 'potency' factor for Russian CT черный (black) and compare the obtained distribution with both normal and geometric (see Fig. 3.1, 3.2) ones.

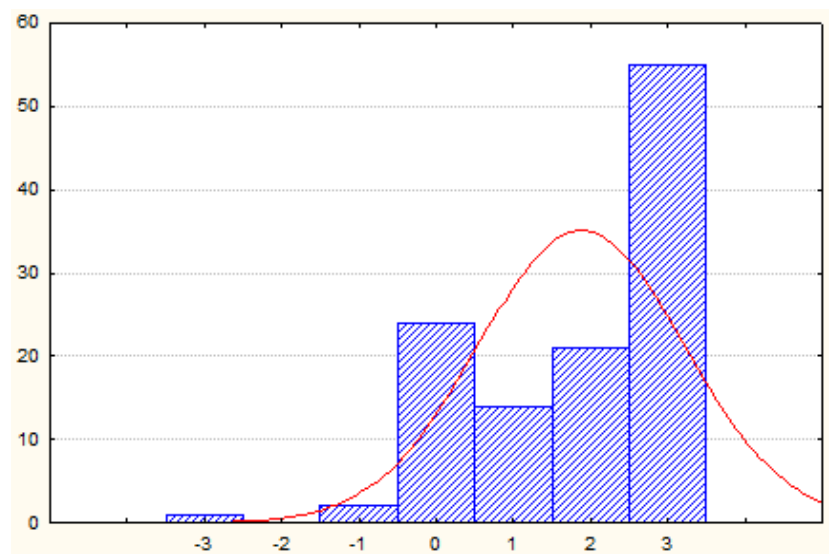

Fig. 1. The histogram for the factor 'potency' with normal distribution (boys' results)

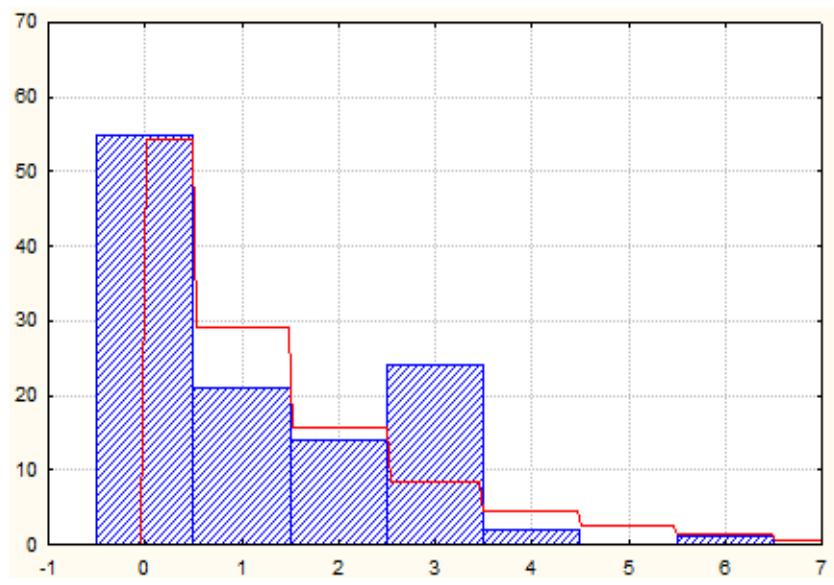

Fig. 2. The histogram for the factor 'potency' with geometric distribution (boys' results)

We deal with a histogram with geometric distribution since it is closer than the normal one. Consequently, it can be concluded that this factor prevails and makes it necessary to give the estimates which would be absent in the case of normal distribution. There is a tendency to associate черный (black) with such characteristics as 'masculinity', 'potency', 'belligerence'. At the same time, the presence of such factors as 'formality' and 'emotionality' in the semantic structure can be considered as a distinctive feature of the inner image of CТ черный (black).

There are also five factors in girls' answers. The factors of evaluation and activity are significant for both girls and boys. However, with respect to other factors we can conclude the following. First, a girl identifies good with the feminine and bad with the masculine. Hence, such scales as MASCULINE and INSINCERE are combined into one factor. In addition, the image of CT черный (black) is influenced by its symbolic use. For this reason there is the second factor as an indication of 
the emotional impact of the color. It is interesting that the fifth factor which we conventionally called 'belligerence' combines such scales as BELLIGERENT and COLD.

The loads of these factors are distributed unevenly. The evaluation factor has the greatest load. The distribution of the estimates for this factor is shown in the graph (see Fig. 3).

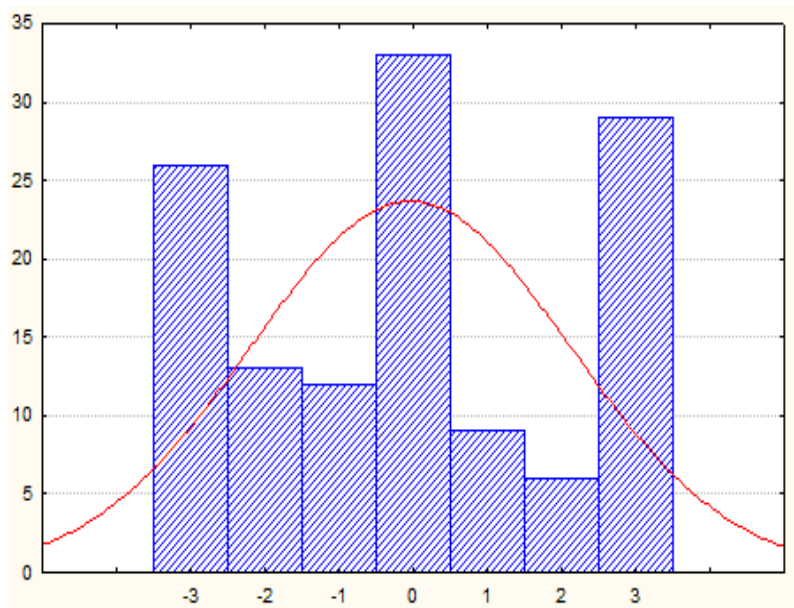

Fig.3 .The histogram for the factor 'evaluation' (girls' results)

The graph shows that the image of CТ черный (black) is ambiguous. Respondents treat it differently, one loves this color, the other does not, and the third treats it absolutely indifferently. It proves that 'color preferences automatically influence our processing of the visual world' [21]. It can be assumed that the personal attitude to black color influenced this distribution.

So, in young people's linguistic consciousness black is strict, formal, strong. Accordingly, young people evaluate it seriously enough trying to abstract from their personal preferences. It is evident by the fact that the 'evaluation' factor does not have the greatest load. At the same time, girls' assessments are more dependent on their individual preferences. In this case there is an identification of CT черный (black) negative characteristics with its masculinity, activity and belligerence.

\section{Conclusion}

The results of our experiment show the specificity of the cultural knowledge about black color's reflection in the consciousness of a native Russian speaker. Black color is quite attractive aesthetically (which is confirmed by such reactions as bright, stylish, business). Many garments and everyday clothes are black. It gives them elegance and external beauty. The color itself is a kind of an ideal. You cannot be blacker than black. As a result, black color is often attributed to the objects of the real world that are not black in order to bring them to the ideal. If we consider black as something related to the inner world of an individual we can talk about a negative attitude to it (associations with death, suffering, pain, etc.). The possible reason for this is closely connected with special conditions of the formation of the Europeans' cultural environment (black looked beautiful, but nothing black, for example, could be eaten). Black toothpaste can be regarded as an analogy. The majority of consumers have a negative attitude to it (the paste is just designed for the eccentric minority). Despite the fact that it looks quite beautiful it can even cause physiological disgust. That means that black separated from the human and unable to make him harm is good while black associated with man is bad.

\section{References}

1. Z. Milojevic, R. Ennis, M. Toscani, K. R. Gegenfurtne, Vision Research. Categorizing natural color distributions, 151, 18 (2018)

2. Y. Hsieh, H. Chiu, Y. Tang, M. Lee, Journal of Inteactive Marketing, Do Colors Change Realities in Online Shopping. 41. 14-27. (2018)

3. A.A. Zalevskaya, Introduction to psycholinguistics (RGGU, Moscow, 32, 1999)

4. F. Sharifian, Language, and Mind: Sociocultural Situatedness. Berlin/New York: Mouton de Gruyter. Distributed, emergent cultural cognition, conceptualisation, and language, R.M. Frank, R.Dirven, T.Ziemke, \& E.Bernandez (eds.) Body, 2. 109-136. (2008)

5. E.A. Tanygina, Journal of psycholinguistics. Moscow: Institute of linguistics of Russian academy of sciences. Inner Image of Russian Colour Term Krasnyi (Red) in the Consciousness of Representatives of Modern Russian Culture, 1 (13). 166-173. (2011)

6. E.A. Tanygina. Vestnic of Tver State University. Phylology. Inner Image of Russian Colour Term Фиолетовый (Purple) in Modern Russian Culture, 4. 218-226. (2011)

7. E.A. Tanygina, Vestnik ISLU. Irkutsk: Published by Irkutsk State Linguistic University. The image of colour in the linguistic consciousness of the native speakers of Russian (the Russian colour term 'pink'), 4 (16). 69-75. (2011)

8. A.A. Zalevskaya, Psycholinguistic research: Word. Text: Selected works (Gnosis, Moscow, 2005)

9. A.P. Vasilevich, Thesis of doctor of philological Sciences, Moscow: Institute of linguistics of Russian academy of sciences. Language picture of the world of color. Research methods and applied aspects, 95 (2003)

10. R.M. Frumkina, Psycholinguistics (ACADEMA, Moscow, 2001)

11. A.P. Guskova, B.V. Sotin, Popular dictionary of the Russian language. Explanatory and encyclopedic (5 thousand articles) (AST-Press. Moscow, 2003)

12. T.F. Efremova, A Large modern dictionary of the Russian language (2006) Retrieved 26, 2018 from: https://www.efremova.info

13. S.I. Ozhegov, N.Yu Shvedova, Explanatory dictionary of the Russian language: 80 thousand words and phraseological expressions (ITI Technology. Moscow, 4, 2007) 
14. T.Yu. Svetlichnaya. Thesis of Philological sciences' kandidate, Pyatigorsk. Comparative linguocultural characteristics of color designation and color perception in English and Russian languages 160 (2003)

15. V.P. Glukhov, Basics of psycholinguistics (ACT: Astrel, Moscow, 2005)

16. A.V. Annenkova, S.V. Lebedeva, Current Issues of Linguistics and Didactics: The Interdisciplinary Approach in Humanities and Social Sciences Psycholinguistic research of creolized advertising texts: age factor, (CILDIAH-2018) SHS Web of Conferences. (2018)

17. M. Chráskaa, M. Chráskováa, Procedia - Social and Behavioral Sciences. Semantic differential and its risks in the measurement of students' attitudes, 217. 821 (2016)

18. V.F. Petrenko, Basics of Psychosemantics. Second edition. Enlarged edition (Peter, Saint Petersburg, 2005)

19. O.S. Zubkova, A.V. Annenkova, MJLTM Perception Peculiarities of Image Advertising Polycode Texts (Some Results of Experimental Research). 7(8) (August). 189-202 (2017)

20.A.A. Gritsanov, Sociology: Encyclopedia (Book House, Minsk, 2003)

21. C. Racey, A. Franklin, NeuroImage The processing of color preference in the brain, 191. 529 (2019) 